\title{
Differentiation between staple line granuloma and recurrence after sublobar resection for primary lung cancer
}

\author{
Natsumi Matsuura, Hitoshi Igai, Fumi Ohsawa, Tomohiro Yazawa, Mitsuhiro Kamiyoshihara \\ Department of General Thoracic Surgery, Japanese Red Cross Maebashi Hospital, Maebashi, Japan \\ Contributions: (I) Conception and design: N Matsuura; (II) Administrative support: H Igai; (III) Provision of study materials or patients: All authors; \\ (IV) Collection and assembly of data: All authors; (V) Data analysis and interpretation: N Matsuura; (VI) Manuscript writing: All authors; (VII) Final \\ approval of manuscript: All authors. \\ Correspondence to: Natsumi Matsuura, MD, PhD. Department of General Thoracic Surgery, Japanese Red Cross Maebashi Hospital, Maebashi \\ 371-0811, Japan. Email: nmori1130@gmail.com.
}

\begin{abstract}
Background: The use of sublobar resection for early-stage lung cancer or frail cases that cannot tolerate radical surgery for primary lung cancer has been increasing. This study aimed to identify the frequency, shape, and course of staple line thickening and granuloma formation after sublobar resection for primary lung cancer, and to identify factors that help distinguish them from recurrent cancer cases.

Methods: The medical records of 64 patients who underwent sublobar resection for primary lung cancer from January 2012 to December 2017 at our institution were retrospectively reviewed. Computed tomography (CT) images taken every 6 months for at least 3 years after surgery were reviewed, and the postoperative course was examined.

Results: Staple line thickening at the time of the first CT scan after surgery was observed in 43 cases $(67.2 \%)$. Of them, linear thickening was seen in 31 cases $(72.1 \%)$, and nodular thickening was seen in 12 cases $(27.9 \%)$. Of these 43 cases, 25 cases were decreased, 8 cases were unchanged and 10 cases showed a tendency to progress during the follow-up period. Of the 64 cases, 7 (10.9\%) had staple line recurrence. Staple line recurrence was significantly correlated with vascular invasion $(\mathrm{P}=0.015)$, surgical margin $(\mathrm{P}=0.013)$, nodular thickening $(\mathrm{P}<0.001)$ and a tendency to show progressive thickening $(\mathrm{P}<0.001)$.

Conclusions: Staple line thickening was observed in many cases of sublobar resection, and most of them were linear thickening. Staple line recurrence should be suspected if nodular thickening appears and shows a tendency to progress.
\end{abstract}

Keywords: Staple line thickening; sublobar resection; staple line recurrence; staple line granuloma

Submitted Oct 11, 2021. Accepted for publication Dec 03, 2021.

doi: $10.21037 /$ jtd-21-1626

View this article at: https://dx.doi.org/10.21037/jtd-21-1626

\section{Introduction}

The standard surgical procedure for early-stage non-small cell lung cancer (NSCLC) is lobectomy with systemic or selective lymph node dissection (1). However, in recent years, the use of sublobar resection such as wedge resection and segmentectomy for early-stage lung cancer with ground glass opacities and small nodules has been increasing $(2,3)$. Sublobar resection is also an effective surgical procedure for frail cases that cannot tolerate radical surgery for primary lung cancer. However, sublobar resection for primary lung cancer is always associated with the risk of local recurrence.

Automatic suturing devices are now widely used in thoracoscopic surgery. They are mainly made of titanium that shows good corrosion resistance in the human body and excellent compatibility with both hard and soft tissues. However, cases with staple line thickenings after lung parenchyma dissection with a stapler are often seen during postoperative follow-up. In those cases, it is very difficult to distinguish between benign granuloma and recurrence of 
lung cancer only with imaging such as computed tomography (CT) or positron emission tomography (PET)-CT.

This study aimed to identify the frequency, shape, and course of staple line thickening and granuloma formation after sublobar resection for primary NSCLC, and to identify factors that help distinguish them from recurrent cancer cases. We present the following article in accordance with the STROBE reporting checklist (available at https:// jtd.amegroups.com/article/view/10.21037/jtd-21-1626/rc).

\section{Methods}

The study was approved by the institutional ethics board of Japanese Red Cross Maebashi Hospital (No. 2021-5) and individual patient consent for this retrospective analysis was waived. The study was conducted in accordance with the Declaration of Helsinki (as revised in 2013).

\section{Patient selection}

From January 2012 to December 2017, a total of 510 patients underwent lung resection for primary lung cancer at our hospital. Data were obtained from the medical records of 122 patients who underwent segmentectomy or wedge resection of lesions during the same period. Of them, cases in which CT scans were taken regularly for at least 3 years after surgery and the images could be verified were included in this study. Finally, 64 patients were enrolled. All patient data were analyzed retrospectively.

Preoperative evaluation consisted of physical examination, blood tests, chest radiography, CT of the chest and abdomen, CT or magnetic resonance imaging (MRI) of the brain, and PET-CT. In our department, the standard curative surgery for primary lung cancer is lobectomy with systemic lymph node dissection. In patients who underwent intentional sublobar resection for primary lung cancer, clinical stage 0-IA1 (Tis-1aN0M0) was confirmed by careful preoperative staging with CT and/or PET-CT. For patients who could not tolerate radical surgery due to complications and poor pulmonary function, sublobar resection was also performed as reduction surgery. Even in that case, only cases with $\mathrm{cN} 0$ were included. If necessary, we sampled hilar lymph nodes for pathological staging.

\section{Surgical procedure}

All patients were operated under general anesthesia in the lateral decubitus position with differential lung ventilation.
All surgeries were performed under thoracoscopy with three or four ports. Specifically, XXS Alexis wound retractors (Applied Medical, Rancho Santa Margarita, CA, USA) were fitted to a $2.0-\mathrm{cm}$ skin incision in the fourth intercostal space at the anterior axillary line and a $1.5-\mathrm{cm}$ skin incision in the sixth intercostal at the anterior axillary line. A $10-\mathrm{mm}$ flexible camera was inserted via the $1.5-\mathrm{cm}$ skin incision in the sixth intercostal space in the mid axillary line. When four ports were used, an additional 15-mm skin incision was made in the seventh intercostal space below the scapula for use as the assistant's port.

In segmentectomy, the resection line was determined by preoperative three-dimensional computed tomography (3D-CT) angiography and bronchography. Segmentectomy was defined as resection of the targeted segment having all the dominant pulmonary vessels and bronchi divided. The inflation-deflation technique was used for segment identification. In almost all cases, intersegmental division was accomplished using only a stapler, but for some patients, cautery was used where necessary. Even in such cases, a stapler was used near the hilum.

\section{Postoperative follow-up}

Postoperative follow-up was conducted at 6-month intervals for at least 5 years after surgery. Follow-up evaluations included physical examination, chest radiography, blood tests including tumor marker levels, CT of the chest and abdomen, and PET-CT if necessary. Chest CT was taken every 6 months in almost all cases with or without contrast agents. Postoperative recurrence was clinically diagnosed by these tests with or without a pathological diagnosis.

\section{Morphology of staple line thickening}

The morphology of staple line thickening is defined as: no thickening, linear thickening or nodular thickening (Figure 1). Linear thickening is defined as uniformly thickening along the staple line, whereas nodular thickening is defined as a nodule that protrudes or surrounds the staple line. Thickening size was measured in the longest diameter perpendicular to the staple line in mediastinal view on CT; thickening was defined as a diameter greater than $3 \mathrm{~mm}$.

\section{Statistical analysis}

Categorical variables were compared using Fisher's exact test. Continuous variables were compared using the $t$-test. 

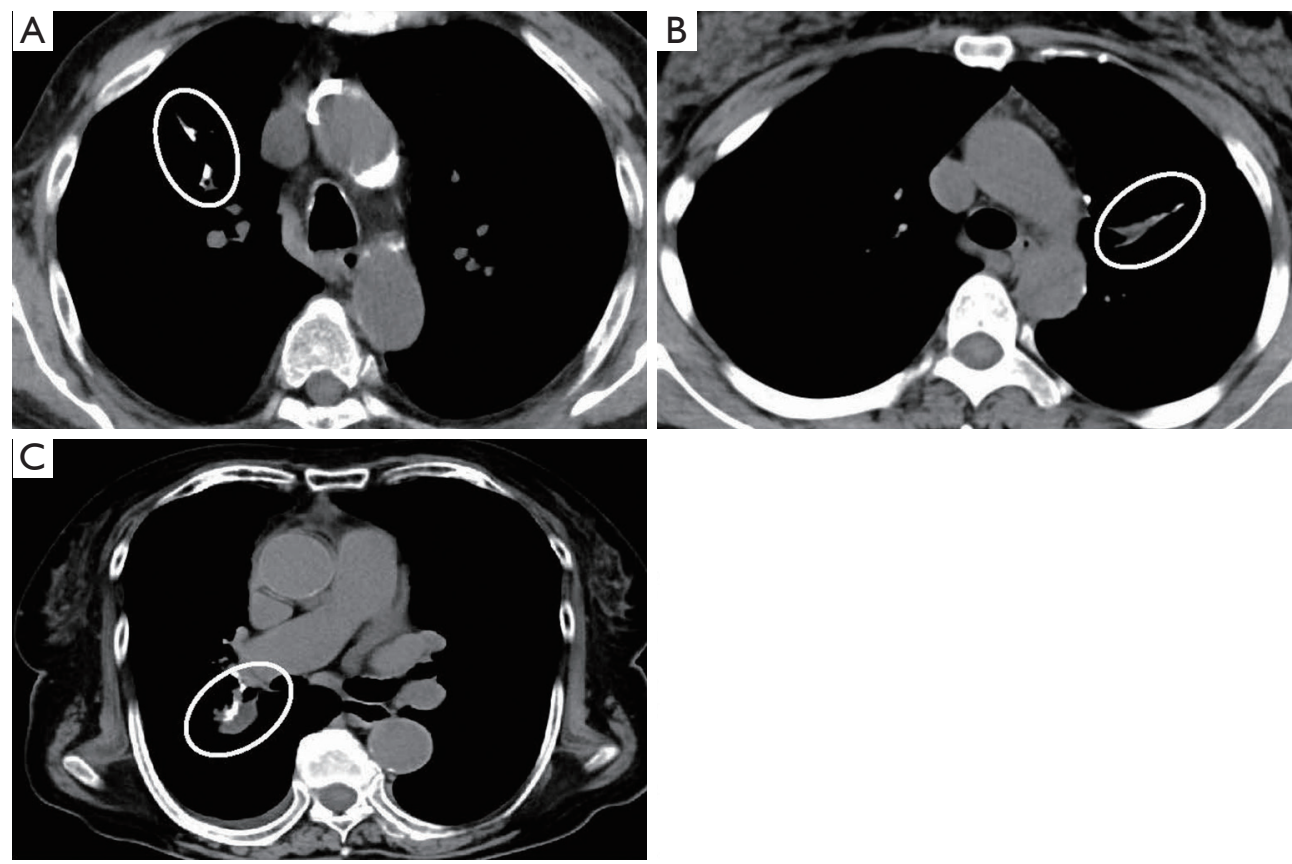

Figure 1 Definition of the morphology of staple line thickening. (A) No thickening, (B) linear thickening, and (C) nodular thickening.

Results were considered significant for values of $\mathrm{P}<0.05$. All statistical analyses were performed with EZR (Saitama Medical Center, Jichi Medical University, Saitama, Japan), which is a graphical user interface for R (The R Foundation for Statistical Computing, Vienna, Austria). More precisely, it is a modified version of $\mathrm{R}$ commander designed to add statistical functions frequently used in biostatistics.

\section{Results}

\section{Patients' characteristics and staple line thickening}

The characteristics and clinicopathological features of all patients [ 38 male, $59.4 \%$; 26 female, $40.6 \%$; mean age 75 years (range, 38-91 years)] are shown in Table 1. The surgical procedure was segmentectomy in 31 patients (48.4\%) and wedge resection in 33 patients $(51.6 \%)$, including 26 intentional sublobar resections. The histopathological type was adenocarcinoma in 50 patients $(78.1 \%)$, squamous cell carcinoma in 11 patients $(17.2 \%)$ and other types in 3 patients (4.7\%), including large cell neuroendocrine carcinoma in 2 patients, and pleomorphic carcinoma in 1 patient. Mean tumor size was $1.9 \mathrm{~cm}$ (range, $0.2-4.5 \mathrm{~cm}$ ) and mean invasive component size was $1.1 \mathrm{~cm}$ (range, 0.2-4.1 cm). Almost all cases underwent PET-CT before surgery and the mean maximum standardized uptake value
(SUV-max) was 2.7 (range, 0-15.5). Comparison of patient characteristics and perioperative outcomes between the segmentectomy and wedge resection groups are shown in Table S1. Nodular thickening was significantly more in wedge resection group (Table S1).

Staple line thickening at the time of the first CT scan after surgery (typically performed 6 months after surgery) was observed in 43 cases (67.2\%). Of them, linear thickening was seen in 31 cases $(72.1 \%)$ and nodular thickening was seen in 12 cases (27.9\%). The mean size of thickening was $10.3 \mathrm{~mm}$ (range, 4-26 mm). Of these 43 cases, 25 were decreased and 8 were unchanged in shape and size during the course. On the other hand, 10 cases showed a tendency to progress during the follow-up period, of which three cases were linear but increased partially to nodules (Figure 2).

PET-CT was taken in 17 cases during postoperative follow-up. Of them, 10 cases, 9 with linear thickening and 1 with nodular thickening, showed no accumulation on the staple line. The remaining 7 cases were 6 cases with staple line recurrence and 1 case with staple line granuloma.

\section{Comparison between patients with and without staple line recurrence}

Comparison of patient characteristics and clinicopathological differences between patients with and without staple line 
Table 1 Characteristics of all patients

\begin{tabular}{|c|c|}
\hline Characteristic & Frequency \\
\hline Age, years & $75 \pm 9.6$ \\
\hline \multicolumn{2}{|l|}{ Sex } \\
\hline Female & $26(40.6)$ \\
\hline Male & $38(59.4)$ \\
\hline \multicolumn{2}{|l|}{ Tumor location } \\
\hline Right upper lobe & $21(32.8)$ \\
\hline Right lower lobe & $10(15.6)$ \\
\hline Left upper lobe & $24(37.5)$ \\
\hline Left lower lobe & $9(14.1)$ \\
\hline \multicolumn{2}{|l|}{ Surgical procedure } \\
\hline Segmentectomy & $31(48.4)$ \\
\hline Wedge resection & $33(51.6)$ \\
\hline \multicolumn{2}{|l|}{ Reason for sublobar resection } \\
\hline Intentional & $26(40.6)$ \\
\hline Unintentional & $38(59.4)$ \\
\hline \multicolumn{2}{|l|}{ Histology } \\
\hline Adenocarcinoma & $50(78.1)$ \\
\hline Squamous cell carcinoma & $11(17.2)$ \\
\hline Others & $3(4.7)$ \\
\hline Tumor size, cm & $1.9 \pm 1.0$ \\
\hline Invasive component size, cm & $1.1 \pm 1.1$ \\
\hline PET-CT, SUV-max & $2.7(0-15.5)$ \\
\hline Surgical margin, mm & $18 \pm 14$ \\
\hline \multicolumn{2}{|l|}{ Staple line thickening } \\
\hline Yes & $43(67.2)$ \\
\hline Linear & $31(72.1)$ \\
\hline Nodular & $12(27.9)$ \\
\hline No & $21(32.8)$ \\
\hline
\end{tabular}

Data are shown as mean \pm standard deviation or number (\%). PET-CT, positron emission tomography-computed tomography; SUV-max, the mean maximum standardized uptake value.

recurrence are shown in Table 2. Staple line recurrence was observed in 7 patients (10.9\%) during the observation period. All were not intentional limited resection. There were no significant differences between the groups in patient characteristics including age, sex, SUV-max on PET-CT, tumor size, surgical procedure and histology. There was no significant difference in lymphatic invasion, but vascular invasion was significantly more common in the staple line recurrence group $(\mathrm{P}=0.027)$. There was significantly less surgical margin in the staple line recurrence group $(\mathrm{P}=0.018)$. Staple line thickening was observed in all cases of the staple line recurrence group, but it was not significant $(\mathrm{P}=0.085)$.

\section{Comparison between with and without staple line recurrence among the cases with staple line thickening}

Comparisons of patients' characteristics and clinicopathological differences between patients with and without staple line recurrence among the cases with staple line thickening are shown in Table 3. There were no significant differences between the groups in patients' characteristics including age, sex, SUV-max of PET-CT, tumor size, surgical procedure, and histology. There were significant differences between the groups in vascular invasion $(\mathrm{P}=0.015)$ and surgical margin $(\mathrm{P}=0.013)$. The thickening type in the staple line recurrence group was all nodular $(\mathrm{P}<0.001)$. All cases in the staple line recurrence group showed a tendency to progress $(\mathrm{P}<0.001)$. Non-staple line recurrence group also had 9 cases showing nodular thickening. Any of the 9 cases finally revealed decreasing of the thickening nodular shadow in the follow-up CT, which allowed us to diagnose the nodular shadow as granuloma.

\section{Details of the staple line recurrence cases}

Table 4 shows the details of the staple line recurrence cases. The mean disease-free interval was 24.4 months (range, 11.9-32.3 months). After 3 to 6 months of followup after showing a tendency to progress, all cases were diagnosed as suspected recurrence. Three of them were diagnosed as recurrence by surgery (wedge resection in 2 cases and completion lobectomy in 1 case). In a case which completion lobectomy was performed, intentional sublobar resection had been performed because the tumor had been diagnosed with non-invasive preoperatively. The remaining 4 cases were clinically diagnosed without a biopsy because it was difficult to diagnose the tumor pathologically due to the tumor location. Figure 3 shows an example of a staple line recurrence case (case 2).

\section{Granuloma cases showing a tendency to progress}

Three of benign granuloma cases showed a tendency to progress, of which 2 cases were at 24 months after 


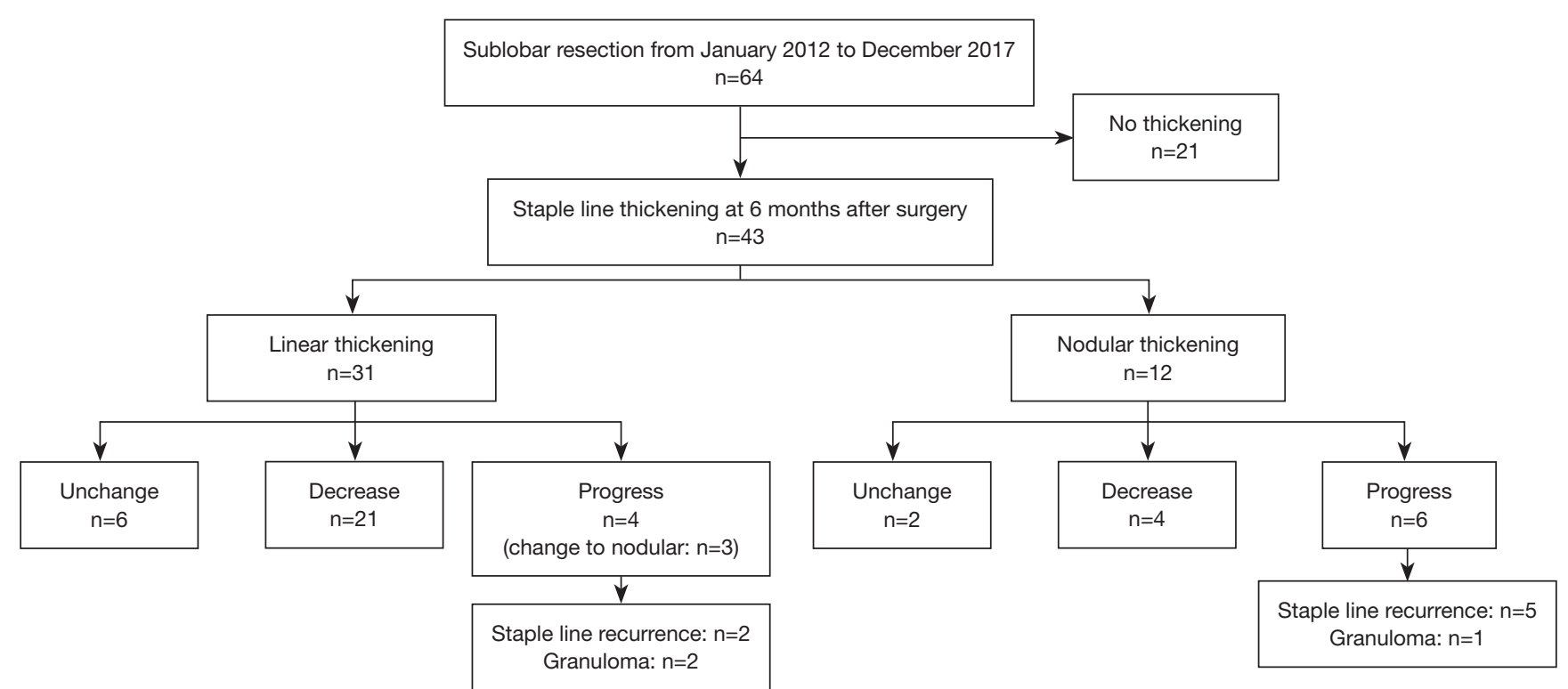

Figure 2 Flow diagram of all patients' results.

Table 2 Characteristics and clinicopathological differences between patients with and without staple line recurrence

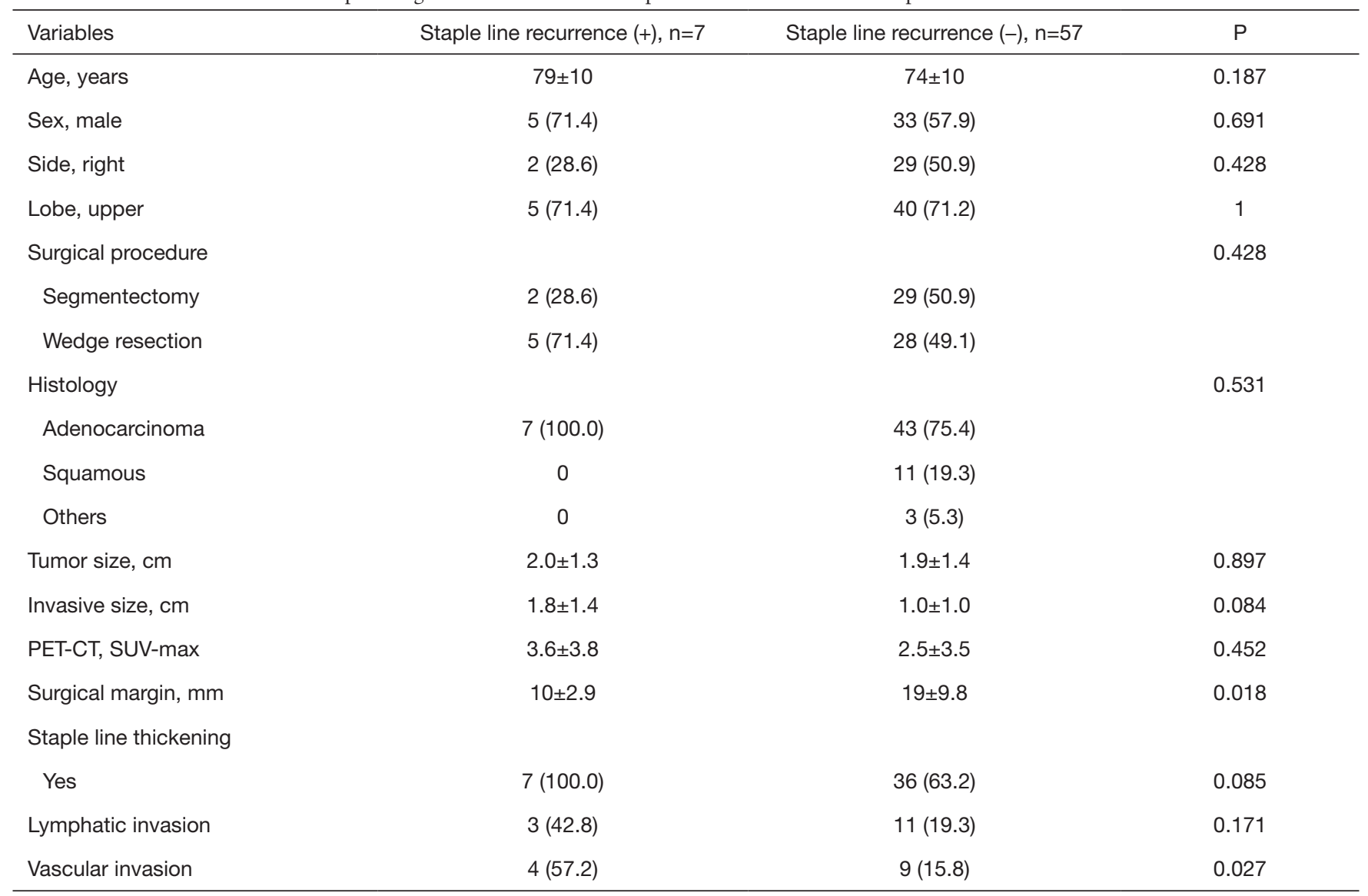

Data are shown as mean \pm standard deviation or number (\%). PET-CT, positron emission tomography-computed tomography; SUV-max, the mean maximum standardized uptake value. 
Table 3 Characteristics and clinicopathological differences between patients with and without staple line recurrence among the cases with staple line thickening

\begin{tabular}{|c|c|c|c|}
\hline Variables & Staple line thickening + recurrence, $n=7$ & Staple line thickening, $n=36$ & $P$ \\
\hline Sex, male & $5(71.4)$ & $19(52.8)$ & 0.437 \\
\hline Age, years & $79 \pm 10$ & $74 \pm 10$ & 0.238 \\
\hline Side, right & $2(28.6)$ & $19(52.8)$ & 0.412 \\
\hline Lobe, upper & $5(71.4)$ & $27(75.0)$ & 1 \\
\hline Surgical procedure & & & 0.211 \\
\hline Segmentectomy & 2 (28.6) & $22(61.1)$ & \\
\hline Wedge resection & $5(71.4)$ & $14(38.9)$ & \\
\hline Histology & & & 0.45 \\
\hline Adenocarcinoma & $7(100.0)$ & $25(69.5)$ & \\
\hline Squamous & 0 & $8(22.2)$ & \\
\hline Others & 0 & $3(8.3)$ & \\
\hline Tumor size, cm & $1.8 \pm 0.9$ & $2.0 \pm 1.3$ & 0.705 \\
\hline Invasive size, $\mathrm{cm}$ & $1.0 \pm 1.1$ & $1.8 \pm 1.4$ & 0.126 \\
\hline PET-CT, SUV-max & $2.9 \pm 3.7$ & $3.6 \pm 3.8$ & 0.651 \\
\hline Surgical margin, mm & $10 \pm 2.9$ & $21 \pm 11.1$ & 0.013 \\
\hline Thickening size, mm & $10 \pm 4.5$ & $12 \pm 7.3$ & 0.387 \\
\hline Thickening type & & & $<0.001$ \\
\hline Linear & 0 & $27(75.0)$ & \\
\hline Nodular & $4(57.2)$ & $6(16.7)$ & \\
\hline Linear $\rightarrow$ nodular & $3(42.8)$ & $3(8.3)$ & \\
\hline \multicolumn{4}{|l|}{ Increase in dimension } \\
\hline Yes & $7(100.0)$ & $3(8.3)$ & $<0.001$ \\
\hline Lymphatic invasion & $3(42.8)$ & $7(19.4)$ & 0.325 \\
\hline Vascular invasion & $4(57.2)$ & $4(11.1)$ & 0.013 \\
\hline
\end{tabular}

Data are shown as mean \pm standard deviation or number (\%). PET-CT, positron emission tomography-computed tomography; SUV-max, the mean maximum standardized uptake value.

surgery and 1 case was at 30 months after surgery. All cases were decreased on the subsequent CT. Figure 4 shows an example of a staple line granuloma case. In this case, a linear thickening had been observed on CT from 6 months after surgery (Figure $4 A$ ). A nodular thickening was seen on CT 24 months after the surgery (Figure $4 B$ ), and abnormal accumulation was observed on PET-CT (Figure 4C), but it decreased on CT 2 months later (Figure 4D).

\section{Discussion}

It is common to use a stapler to dissect the lung parenchyma during wedge resection and segmentectomy, and now that the number of sublobar resection cases is increasing, the chances of seeing postoperative stapler line thickening are increasing. In the present study, staple line thickening at the time of the first CT scan after surgery (typically performed 6 months after surgery) was observed in $67.2 \%$ of cases. 


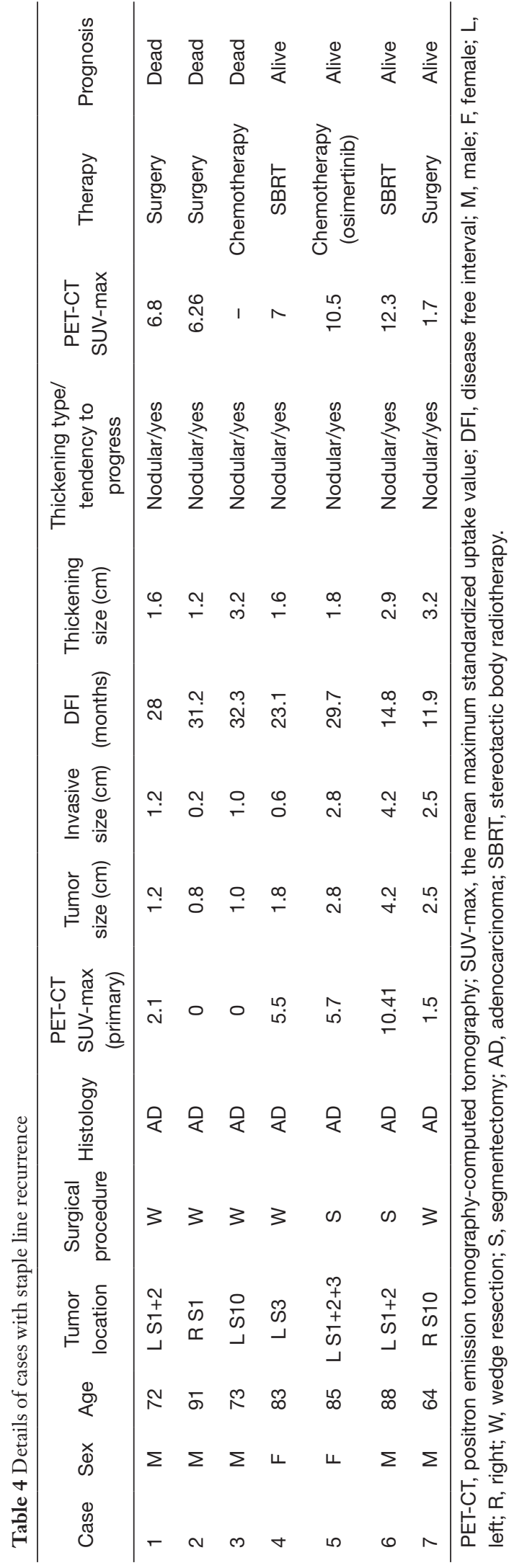

Sun et al. (4) also reported that $78.2 \%$ of staple lines of patients who underwent limited resection for NSCLC showed thickening of $2 \mathrm{~mm}$ or greater on initial postoperative scans. This indicates that staple line thickening is often observed on postoperative CT and is usually followed up as a normal biological reaction. However, when it shows a tendency to progress over time, local recurrence is suspected.

Granulation after sublobar resection has been reported (5-9), but the reason why granulation is more common in wedge resection or segmentectomy rather than after lobectomy is considered to be the atelectasis causing an imbalance of blood flow and ventilation or poor wound healing associated with dissection of relatively thick lung parenchyma. The titanium used in staples has excellent safety and biohistocompatibility, therefore, the reports of foreign body reactions to titanium are extremely rare. There have also been some reports that infection involving the staple line was a factor in the formation of granuloma $(10,11)$.

When the staple line has been thickened and shows a tendency to progress, it is very difficult to distinguish between a benign granuloma and recurrence of lung cancer (11). In the present study, staple line recurrence was significantly correlated with vascular invasion, surgical margin, nodular thickening, and a tendency for thickening to progress. Although it is essential to secure a sufficient margin as far as possible in sublobar resection, it can be difficult when passive limited resection is performed. In the present study, although the positive predictive value for cancer recurrence at the site of staple line thickening was only $16.3 \%$, it included recurrent cases that certainly required examination. Based on the results of this study, patients with staple line thickening and predisposing factors for recurrence (such as vascular invasion and inadequate surgical margin) should be actively followed up for further scrutiny. When cancer recurrence is suspected, PET-CT is one of the useful and non-invasive imaging modalities. The sensitivity of PET-CT for lung cancer is reported to be 83$96 \%$ and the specificity is reported to be $78-91 \%(12,13)$. However, inflammatory diseases and infectious diseases may also show relatively high abnormal accumulation (14), so it is reported that PET-CT cannot differentiate a granuloma from staple line recurrence $(6,9,11)$. In the present study, the SUV-max values on PET-CT in cancer recurrent cases were 1.7 to 12.3 ; in particular, 5 of the cases had a high accumulation of 5 or more. The cut-off value of SUVmax when distinguishing between benign and malignant is usually 2.5 (15), which can be an important clue for further examination and biopsy. However, one of the recurrent 

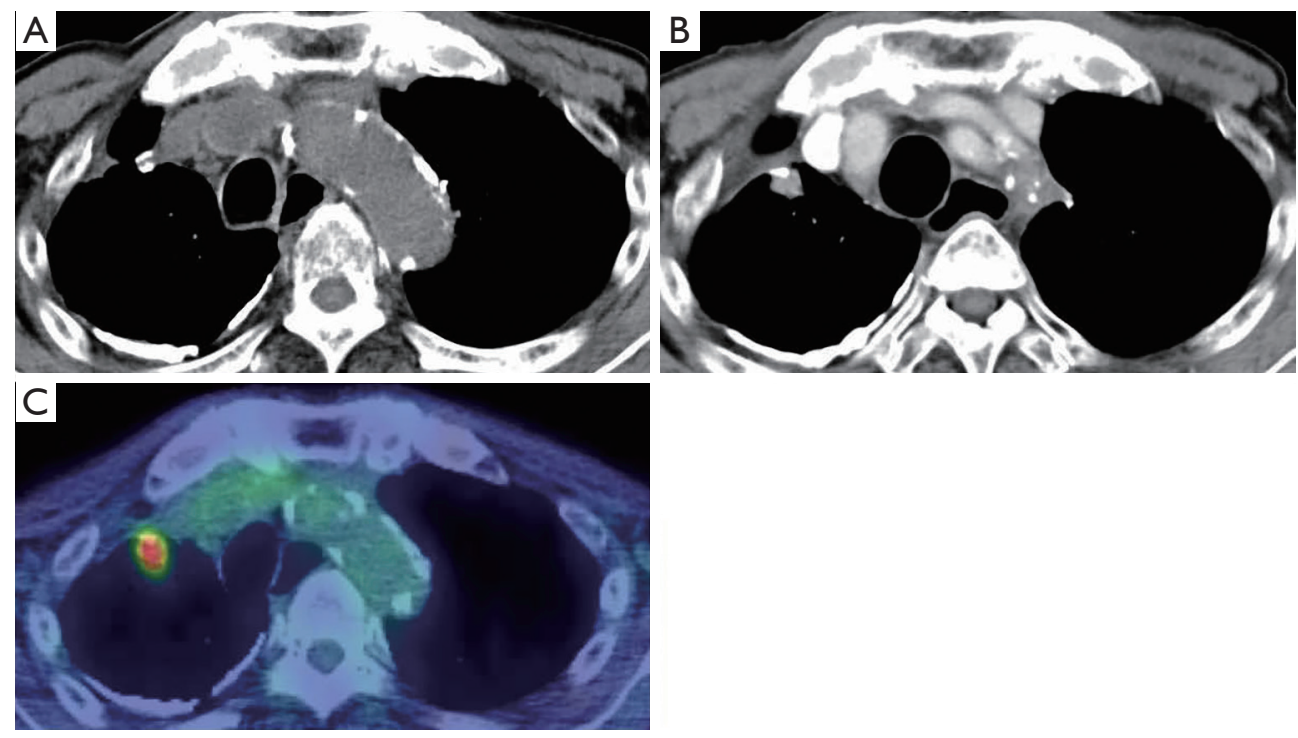

Figure 3 Staple line recurrence. (A) Twenty-four months after surgery. (B) Thirty months after surgery. CT shows a nodule along the staple line (12 mm in diameter). (C) PET-CT shows abnormal accumulation. SUV-max is 6.26. CT, computed tomography; PET, positron emission tomography; SUV-max, the maximum standardized uptake value.
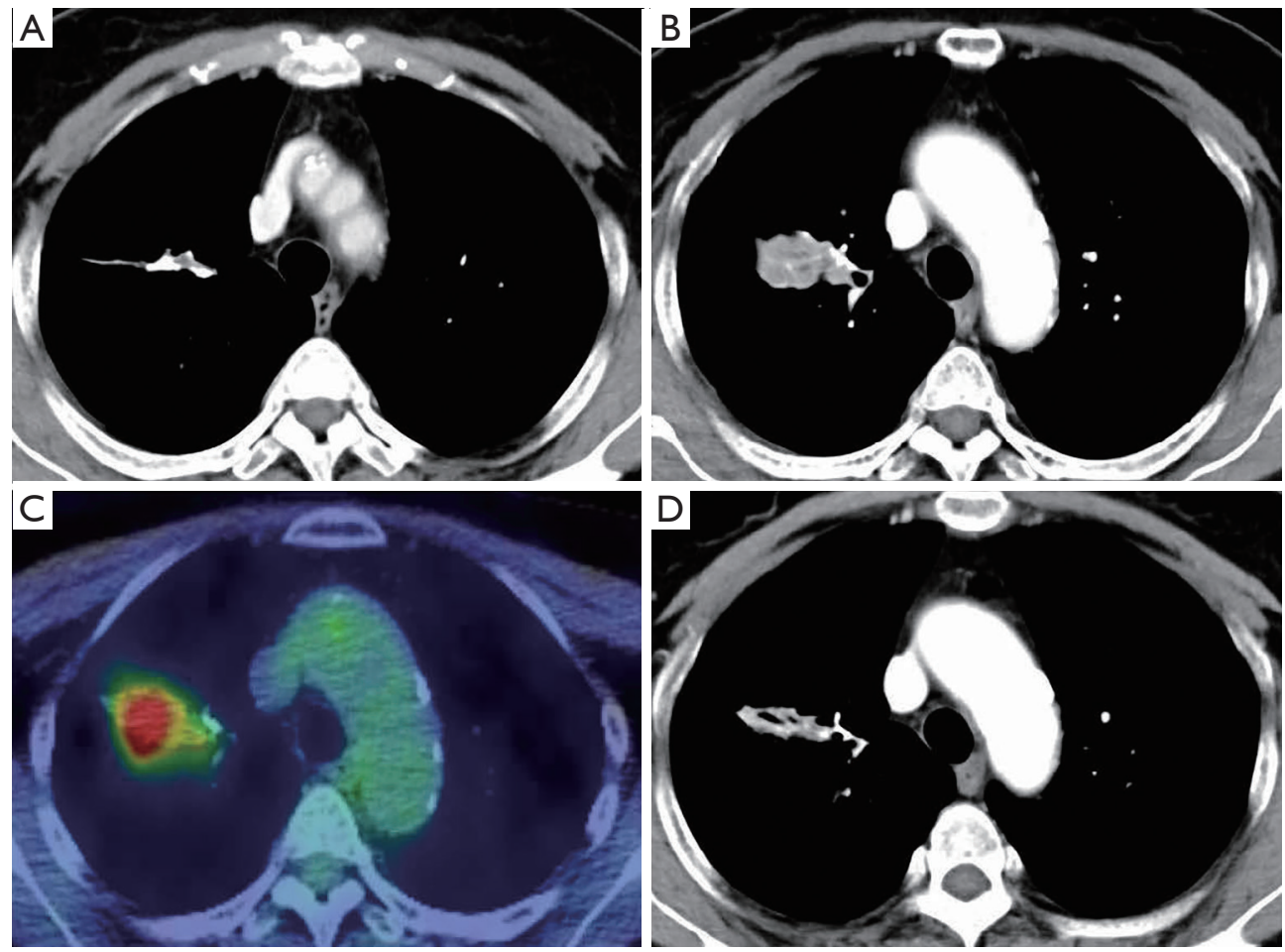

Figure 4 Staple line granuloma. (A) Six months after surgery. (B) Twenty-four months after surgery. CT shows a nodule along the staple line (22 mm in diameter). (C) PET-CT shows abnormal accumulation. SUV-max is 6.80. (D) Two months later. The size of thickening has decreased. CT, computed tomography; PET, positron emission tomography; SUV-max, the maximum standardized uptake value. 
cases had a low SUV-max value of 1.7 , which indicates that recurrence cannot be distinguished only by SUV-max value.

Usuda et al. (16) reported the usefulness of diffusionweighted magnetic resonance imaging (DWI) for differentiation of suture recurrence and suture granuloma after resection for lung cancer. Mizukami et al. (6) and Mizuno et al. (17) reported differences in morphology. Staple line granuloma shows a smooth marginated mass in contact with the staple line. On the other hand, staple recurrence grows concentrically or radially from the staple line and the edges are irregular. In the present cases, for example, staple recurrence was formed on the edge of the staple line (Figure 2). It is still difficult to distinguish by morphology alone, but in most of the present cases, the granuloma had a smooth margin (Figure 1), which may help in the differentiation.

There are some reports of cases diagnosed by CTguided fine needle aspiration biopsy (FNAB) $(6,8)$, but it is often difficult in cases deep in the lung or near the hilum, and there also may be differences between institutions. In the present cases, none underwent biopsy. However, completion surgery is often technically difficult and with various risks, so caution should be exercised in the indications for surgery. Moreover, there is a need to avoid unnecessarily lengthening the follow-up period and causing systemic disease in recurrent cancer cases. Biopsy is a useful diagnostic method in some cases.

This study has some limitations. First, this was a retrospective and single-institution study. Second, the total number of cases was relatively small; in particular, there were only 7 cases of recurrence. Thus, multivariate analysis could not be performed to identify factors associated with recurrence. A prospective, multicenter study is required.

In conclusion, staple line thickening is observed in many cases of sublobar resection, most of which are linear. Recurrence should be suspected if nodular thickening appears and shows a tendency to progress. More cases need to be examined to find out how to distinguish benign granuloma from cancer recurrence.

\section{Acknowledgments}

Funding: None.

\section{Footnote}

Reporting Checklist: The authors have completed the STROBE reporting checklist. Available at https://jtd. amegroups.com/article/view/10.21037/jtd-21-1626/rc

Data Sharing Statement: Available at https://jtd.amegroups. com/article/view/10.21037/jtd-21-1626/dss

Peer Review File: Available at https://jtd.amegroups.com/ article/view/10.21037/jtd-21-1626/prf

Conflicts of Interest: All authors have completed the ICMJE uniform disclosure form (available at https://jtd.amegroups. com/article/view/10.21037/jtd-21-1626/coif). HI serves as an unpaid editorial board member of fournal of Thoracic Disease from August 2016 to July 2022. The other authors have no conflicts of interest to declare.

Etbical Statement: The authors are accountable for all aspects of the work in ensuring that questions related to the accuracy or integrity of any part of the work are appropriately investigated and resolved. The study was conducted in accordance with the Declaration of Helsinki (as revised in 2013). The study was approved by the institutional ethics board of Japanese Red Cross Maebashi Hospital (No. 2021-5) and individual patient consent for this retrospective analysis was waived.

Open Access Statement: This is an Open Access article distributed in accordance with the Creative Commons Attribution-NonCommercial-NoDerivs 4.0 International License (CC BY-NC-ND 4.0), which permits the noncommercial replication and distribution of the article with the strict proviso that no changes or edits are made and the original work is properly cited (including links to both the formal publication through the relevant DOI and the license). See: https://creativecommons.org/licenses/by-nc-nd/4.0/.

\section{References}

1. Ginsberg RJ, Rubinstein LV. Randomized trial of lobectomy versus limited resection for T1 N0 non-small cell lung cancer. Lung Cancer Study Group. Ann Thorac Surg 1995;60:615-22; discussion 622-3.

2. Okada $M$, Koike T, Higashiyama $M$, et al. Radical sublobar resection for small-sized non-small cell lung cancer: a multicenter study. J Thorac Cardiovasc Surg 2006;132:769-75.

3. Suzuki K, Koike T, Asakawa T, et al. A prospective radiological study of thin-section computed tomography to predict pathological noninvasiveness in peripheral clinical 
IA lung cancer (Japan Clinical Oncology Group 0201). J Thorac Oncol 2011;6:751-6.

4. Sun B, Kamel MK, Nasar A, et al. Staple Line Thickening After Sublobar Resection: Reaction or Recurrence? Ann Thorac Surg 2020;109:1670-6.

5. Fink G, Herskovitz P, Nili M, et al. Suture granuloma simulating lung neoplasm occurring after segmentectomy. Thorax 1993;48:405-6.

6. Mizukami Y, Takahashi Y, Adachi H. Pulmonary StapleStump Granuloma After Segmentectomy: Two Case Reports and Comparison with Cases of Stump Recurrence. Am J Case Rep 2019;20:1049-56.

7. Tomita M, Matsuzaki Y, Edagawa M, et al. Pulmonary granuloma possibly caused by staples after video-assisted thoracoscopic surgery. Ann Thorac Cardiovasc Surg 2003;9:123-5.

8. Yüksel M, Akgül AG, Evman S, et al. Suture and stapler granulomas: a word of caution. Eur J Cardiothorac Surg 2007;31:563-5.

9. Okazaki M, Sano Y, Mori Y, et al. Two cases of granuloma mimicking local recurrence after pulmonary segmentectomy. J Cardiothorac Surg 2020;15:7.

10. Miyauchi S, Maki Y, Ueno T, et al. Two cases of inflammatory tumor and nontuberculous mycobacteriosis around the staple line after lung cancer surgery. Jpn J Chest Surg 2017;31:598-603.

11. Matsuoka K, Yamada T, Matsuoka T, et al. Nodule around the staple line after pulmonary resection: benign granuloma or cancer recurrence? Indian J Thorac

Cite this article as: Matsuura N, Igai H, Ohsawa F, Yazawa T, Kamiyoshihara M. Differentiation between staple line granuloma and recurrence after sublobar resection for primary lung cancer. J Thorac Dis 2022;14(1):26-35. doi: 10.21037/jtd21-1626
Cardiovasc Surg 2019;35:569-74.

12. Chien CR, Liang JA, Chen JH, et al. [(18)F]

Fluorodeoxyglucose-positron emission tomography screening for lung cancer: a systematic review and metaanalysis. Cancer Imaging 2013;13:458-65.

13. Gould MK, Maclean CC, Kuschner WG, et al. Accuracy of positron emission tomography for diagnosis of pulmonary nodules and mass lesions: a meta-analysis. JAMA 2001;285:914-24.

14. Grogan EL, Deppen SA, Ballman KV, et al. Accuracy of fluorodeoxyglucose-positron emission tomography within the clinical practice of the American College of Surgeons Oncology Group Z4031 trial to diagnose clinical stage I non-small cell lung cancer. Ann Thorac Surg 2014;97:1142-8.

15. Bryant AS, Cerfolio RJ. The maximum standardized uptake values on integrated FDG-PET/CT is useful in differentiating benign from malignant pulmonary nodules. Ann Thorac Surg 2006;82:1016-20.

16. Usuda K, Iwai S, Yamagata A, et al. Differentiation between suture recurrence and suture granuloma after pulmonary resection for lung cancer by diffusion-weighted magnetic resonance imaging or FDG-PET / CT. Transl Oncol 2021;14:100992.

17. Mizuno K, Ohde Y, Hayashi S, et al. Clinical differentiation in stump granuloma and stump recurrence after lung resection for malignancy using a stapler. Jpn J Lung Cancer 2017;57:826-31. 


\section{Supplementary}

Table S1 Characteristics and clinicopathological differences between the segmentectomy group and the wedge resection group

\begin{tabular}{|c|c|c|c|}
\hline Variables & Segmentectomy, $n=31$ & Wedge resection, $\mathrm{n}=33$ & $P$ \\
\hline Sex, male & $16(51.6)$ & $22(66.7)$ & 0.309 \\
\hline Age, years & $73 \pm 11$ & $76 \pm 8$ & 0.417 \\
\hline Side, right & 12 & $19(52.8)$ & 0.144 \\
\hline Lobe, upper & $24(77.4)$ & $21(63.6)$ & 0.28 \\
\hline Histology & & & 0.557 \\
\hline Adenocarcinoma & $26(83.9)$ & $24(72.7)$ & \\
\hline Squamous & $4(12.9)$ & $2(6.1)$ & \\
\hline Others & $1(3.2)$ & $7(21.2)$ & \\
\hline Tumor size, $\mathrm{cm}$ & $1.8 \pm 1.0$ & $1.9 \pm 1.8$ & 0.82 \\
\hline Invasive size, $\mathrm{cm}$ & $1.1 \pm 1.3$ & $1.1 \pm 0.8$ & 0.866 \\
\hline PET, SUV-max & $2.7 \pm 3.6$ & $2.6 \pm 3.5$ & 0.921 \\
\hline Pathological stage & & & 0.012 \\
\hline 0 & $10(32.3)$ & $3(9.1)$ & \\
\hline IA & $17(54.8)$ & $29(87.9)$ & \\
\hline IB & $1(3.2)$ & $1(3.0)$ & \\
\hline$\geq 2$ & $3(9.7)$ & 0 & \\
\hline Surgical margin, mm & $18 \pm 10.6$ & $7.7 \pm 4.9$ & $<0.001$ \\
\hline Staple line thickening & & & 0.114 \\
\hline Yes & $24(77.4)$ & $19(57.6)$ & \\
\hline Thickening type & & & 0.012 \\
\hline Linear & $19(61.3)$ & $8(24.2)$ & \\
\hline Nodular & $5(16.1)$ & $11(33.3)$ & \\
\hline \multicolumn{4}{|l|}{ Staple line recurrence } \\
\hline Yes & $2(6.5)$ & $5(15.2)$ & 0.428 \\
\hline Lymphatic invasion & $9(29.0)$ & $5(15.2)$ & 0.232 \\
\hline Vascular invasion & $4(12.9)$ & $6(18.2)$ & 0.734 \\
\hline
\end{tabular}

Data are shown as mean \pm standard deviation or number (\%). PET-CT, positron emission tomography-computed tomography; SUV-max, the mean maximum standardized uptake value. 